\title{
Liver radiofrequency ablation as emergency treatment for a ruptured hepatocellular carcinoma: a case report
}

\author{
Alessandra Bertacco ${ }^{1,2}$, Francesco D'Amico ${ }^{1,2^{*}}$, Maurizio Romano ${ }^{1}$, Michele Finotti ${ }^{1}$, Alessandro Vitale ${ }^{1}$ \\ and Umberto Cillo ${ }^{1}$
}

\begin{abstract}
Background: Hemoperitoneum is a possible complication of hepatocellular carcinoma that may require emergency surgery as an alternative to radiological locoregional therapies.

Case presentation: We present a case report of a 78-year-old white man with alcoholic-related cirrhosis and a multifocal hepatocellular carcinoma. An abdominal computed tomography scan showed multiple and bilateral foci of bleeding from broken liver cancer. He was urgently transferred from our radiology unit to our operating room for massive hemoperitoneum. A middle line laparotomy detected a massive hemoperitoneum. His liver was cirrhotic and completely subverted by a tumor; there were two spontaneous bleeding lacerations on segments II and IV, which were uncontrollable with conventional hemostatic techniques. Therefore, it was decided to carry out the coagulation of the multiple vascular afferents of each single mass by means of radiofrequency ablation cycles performed circumferentially on both nodules for a total of 40 minutes. Hemostasis was achieved; the radiofrequency ablation controlled the bleeding from his ruptured hepatocellular carcinoma. He was transferred to our intensive care unit for postoperative monitoring in terms of hemodynamic stability. On postoperative day 2 he was discharged from our intensive care unit.

Conclusions: Multifocal bleeding hepatocellular carcinoma still has an extremely high mortality. The angiographic control of multiple bilateral bleeding lesions can be extremely difficult and can be contraindicated by the location of the lesions and by the overall clinical condition of the patient. In this case, treatment with radiofrequency ablation has proven to be effective in the control of multiple and bilateral hepatic lesions. This particular technique allowed us to attack the lesion at the level of the vascular pedicle in order to control the bleeding.
\end{abstract}

Keywords: HCC ruptured, Radiofrequency ablation, Liver bleeding, Case report

\section{Background}

Spontaneous liver bleeding (SLB) is a rare lifethreatening complication that warrants a timely diagnosis and effective control of hemorrhage. Hepatocellular carcinoma (HCC), after benign adenoma, is the most frequent underlying pathology of SLB [1]. HCC is the fifth most prevalent cancer in the world. More than $80 \%$ of HCCs develop in cirrhotic livers. Liver resection and liver transplantation (LT) offer the best chance of

\footnotetext{
* Correspondence: drdamico@hotmail.com

'Department of Surgery, Oncology and Gastroenterology (DISCOG),

Hepatobiliary Surgery and Liver Transplantation, Padua University, Padua, Italy

${ }^{2}$ Department of Surgery, Division of Transplantation and Immunology, Yale

University, New Haven, Connecticut, USA
}

cure [2]. Spontaneous HCC rupture is not a rare first presentation of the disease and bleeding is one of the most serious complications. While HCC has often been detected precociously in recent years, an incidence of ruptured HCC of 3 to $15 \%$ has been reported and its in-hospital mortality rate ranges from 7 to $25 \%$ in the acute phase [2,3]. Spontaneous HCC rupture is likely to occur in patients with advanced stage HCC with reported incidences of $10.0 \%$ in Japan [4], $12.4 \%$ in Thailand [5], and approximately $3.0 \%$ in the UK [6]. Patients with ruptures could have favorable long-term outcomes, particularly those without decompensated liver 
cirrhosis or portal venous thrombosis and who are eligible for curative treatment [7]. The mechanism of spontaneous rupture of $\mathrm{HCC}$ remains unclear, but the risk of bleeding can be explained by modification in the feeding vessels of the tumor, venous congestion, and coagulopathy due to underlying cirrhosis $[8,9]$. The management of ruptured HCC is composed of two steps: bleeding control and specific tumor treatment usually at a distance from the acute bleeding episode [1]. There is still a debate concerning the best approach in cases of HCC rupture. The treatment includes emergency liver resections, interventional transcatheter arterial embolization (TAE), packing, and even LT, depending on the hemodynamic stability of the patient, tumor stage, and liver function. Open surgery was the main method used to treat HCC rupture from the 1960s to the 1980s $[10,11]$. Recently, a survival benefit of TAE has been reported [12, 13]. Radiofrequency ablation (RFA) was described in rare clinical cases or short series [14], and therefore has not been validated. The theoretical advantage is to treat the underlying tumor if the size is compatible with current indications.

\section{Case presentation}

We present a case report of a 78-year-old white man with alcoholic cirrhosis and multifocal HCC with ascites and portosystemic encephalopathy. In his past history (2 years before) he had a wedge resection of segment II for HCC (G2). Since then he was followed-up annually, including a computed tomography (CT) scan, by our medical department. He was not considered for LT due his advanced age. He presented to our emergency room for ascitic decompensation with abdominal tension and lower limb edema. During his recovery, his hematocrit suddenly dropped (hemoglobin from $9.3 \mathrm{~g} / \mathrm{L}$ to $6.7 \mathrm{~g} / \mathrm{L}$ in 3 hours); an abdominal CT scan showed multiple and bilateral foci of $\mathrm{HCC}$ with evidence of acute bleeding from one of them (Fig. 1). His Model for End-Stage
Liver Disease (MELD) score was 19; his Child-Pugh score was $\mathrm{C} 11$; total bilirubin was $8 \mathrm{mg} / \mathrm{dl}$ and alphafetoprotein (AFP) 604 ug/L. He was hemodynamically unstable and compromised so he was urgently transferred to our operating room (OR) for hemorrhagic shock. A middle line laparotomy was performed and a massive hemoperitoneum was found $(4 \mathrm{~L})$. His liver was cirrhotic with recanalization of umbilical vein and collateral vessels. His liver was completely subverted by a tumor and there was bleeding from two lacerations on segments II and IV, which was uncontrollable with conventional hemostatic techniques (argon beam, oxidized regenerated cellulose, and fibrin glue). Due to his condition, his poor liver function reserve, and the multifocal tumor it was decided to carry out the coagulation of the multiple vascular afferents of each single mass by RFA. Multiple RFA cycles were performed circumferentially on both nodules for a total of 40 minutes. Hemostasis was achieved; the RFA controlled the bleeding from our patient's ruptured HCC (Fig. 2). Operation time was 90 minutes. During the operation he needed transfusions of three packed red blood cells (PRBC) transfusions and drug support with noradrenaline 0.4 gamma $/ \mathrm{Kg} /$ minute and dopamine 2 gamma $/ \mathrm{kg} /$ minute. He was transferred to our intensive care unit (ICU) for postoperative monitoring. On postoperative day (POD) 2 he was discharged and reassigned to our medical floor, without vasopressor therapy. His peak postoperative transaminase levels were aspartate aminotransferase (AST) $659 \mathrm{UI} / \mathrm{L}$ and alanine aminotransferase (ALT) $260 \mathrm{UI} / \mathrm{L}$ but he did not develop liver failure. The main problem was the hepatorenal syndrome that occurred on POD9 due to the progression of his underlying liver disease; he did not need renal replacement therapy. He was discharged from our medical department; his general condition was satisfactory. He was followed-up in our clinic by our palliative care team, but unfortunately he died 2 months later due to a progression of his disease.
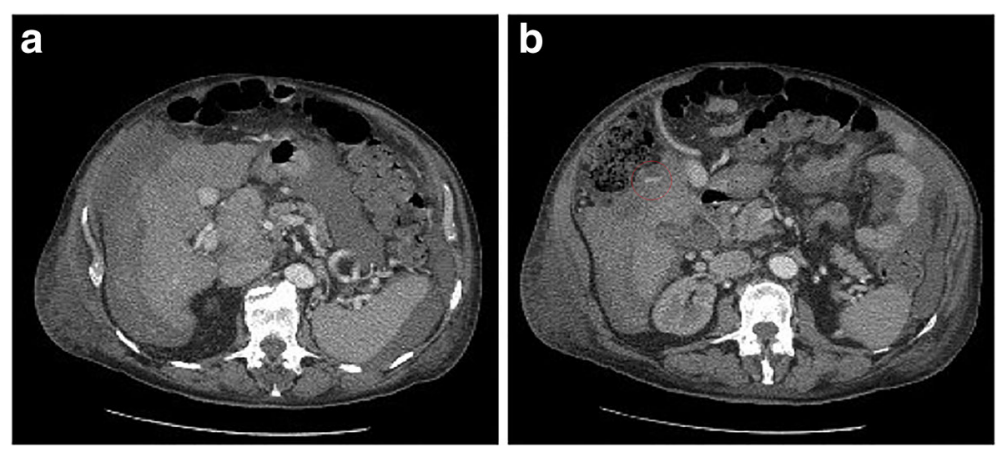

Fig. 1 Abdominal computed tomography scan with intraperitoneal fluid with blood density (a), and evidence of the contrast leak (white spread) in proximity of the right lobe of the liver (b) 


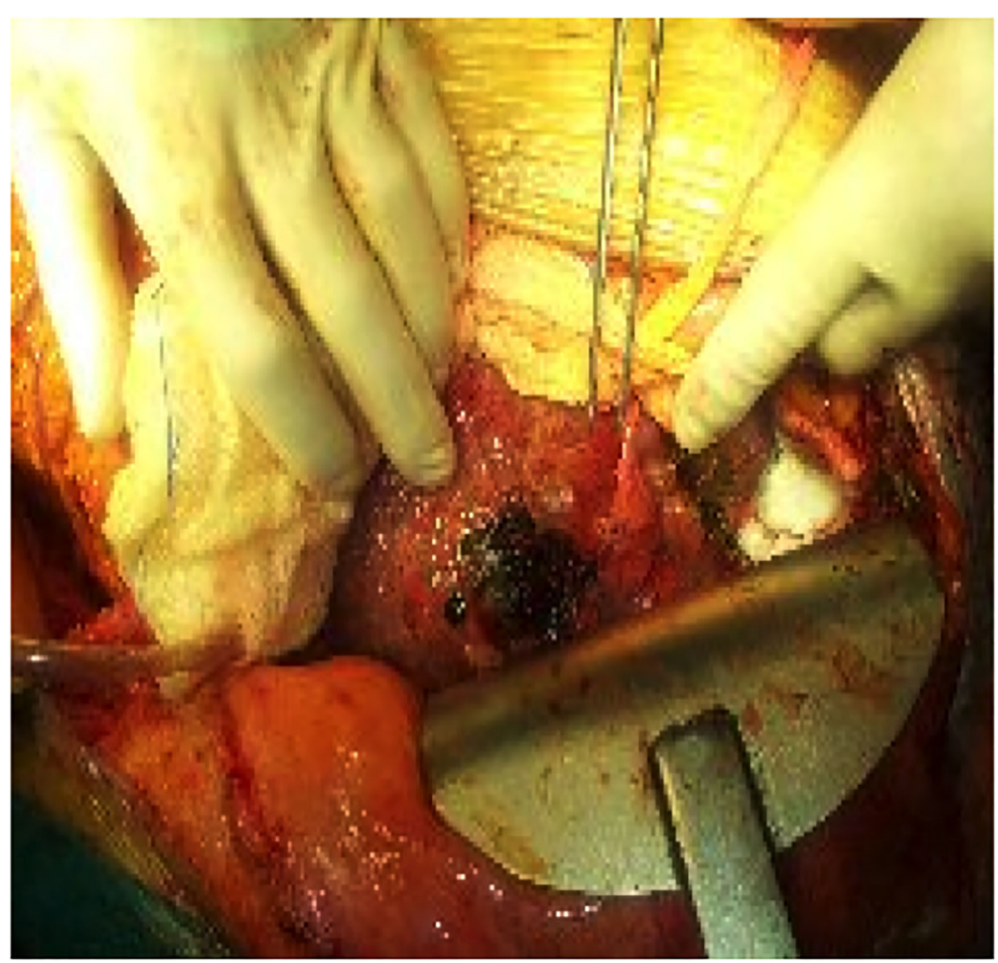

Fig. 2 Final result of bleeding control from ruptured hepatocellular carcinoma using radiofrequency ablation

\section{Discussion}

Recent progress in diagnostics has facilitated early identification of HCC. Despite this advancement, some patients continue to be diagnosed at a late stage. Ruptured HCC often represents a more advanced tumor stage, as reflected by the tumor size, tumor number, vascular invasion, and tumor marker values. Furthermore, a comparison between ruptured $\mathrm{HCC}$ and non-ruptured HCC revealed that spontaneous tumor rupture was more frequent among patients with a poor liver functional reserve, as reflected by Child-Pugh grade and liver damage classification [2]. Diagnosing ruptured HCC can be difficult, although the development of imaging studies have improved the rate of preoperative diagnosis. An abdominal-pelvic CT scan is currently the most important radiological investigation to perform as the patient becomes hemodynamically stable [1]. The second step is the control of bleeding: whatever technique is chosen, the main goal is to obtain effective hemostasis and stabilize cardiorespiratory reserve. The tumor treatment is secondary: there is actually no evidence to recommend an invasive approach, such as emergency liver resections. Many scholars tend to choose emergency liver resection because it may effectively restore complete hemostasis and at the same time resect the primary lesions. However, even if the bleeding is stopped temporarily, death due to liver function failure and/or other comorbidity of the patient are important reasons to consider for patient outcomes [15]. Most patients lack the functional reserve to tolerate surgery and the disease is often surgically unresectable at the time of rupture. Hepatic reserve should be evaluated once hemostasis is achieved, and only when selected patients are in a stable phase should tumor treatment, such as elective hepatectomy or TAE, be performed [16]. TAE in stable patients with ruptured $\mathrm{HCC}$ and active bleeding is currently the treatment of choice, even if the optimal standards and therapeutic values of treatment have not reached a unified consensus. Its advantage lies in its simplicity, minimal invasiveness, fast hemostasis, and rapid postoperative recovery. TAE followed by elective hepatectomy is also considered an effective strategy for patients with ruptured $\mathrm{HCC}$ [4]. In selected patients, prolonged survival is also possible using TAE as initial therapy with or without a delayed resection and systemic therapy [17]. However, TAE is not always feasible without major procedural complication. A recent study evaluated the outcome of emergent embolization of ruptured $\mathrm{HCC}$; patients with a Child-Pugh score of $\mathrm{B} / \mathrm{C}$, those with a MELD of 10 or more, and patients with portal vein thrombosis prior to embolization had a higher risk of death [18]. If embolization is unavailable and patients are hemodynamically unstable, then emergency surgery may be necessary. The goals are rapid and effective control of bleeding. The preferred technique of hemostasis is packing, after temporary clamping of the hepatic 
pedicle. The techniques of suture, intratumoral injection of alcohol [19], and ligation of the proper hepatic artery [5] should no longer be performed because of reports of low efficacy and high morbidity. Patients with a poor liver function reserve cannot tolerate surgical resection or aggressive angiographic intervention. Therefore, Child-Pugh and MELD, which reflect reserved hepatic function, could be important pretreatment factors. In some cases, conservative treatments are selected, but recent studies showed that this may not be the best approach. A study from Taiwan [20] concluded that a conservative approach was associated with a significantly worse survival rate compared with hepatectomy alone or in combination with TAE. Jin et al. [21] suggested that the post-treatment outcomes of surgery or TAE are better than those of supportive care in these patients, and that surgical hemostasis might provide better survival benefit than TAE. In this setting, tumor RFA is a possible therapeutic policy that has exhibited significant progress in the last decade. In recent years, the efficacy of this method for achieving hepatic hemostasis has become greatly appreciated in the treatment of liver trauma and in cases of ruptured liver tumors [1]. RFA is a minimally invasive treatment and can be performed laparoscopically or during open surgery in patients who are in poor general condition or who have liver dysfunction. RFA uses pulsed radiofrequency current to quickly heat and ablate large volumes of tissue. At temperatures above $60{ }^{\circ} \mathrm{C}$, cellular proteins rapidly denature and coagulate. The ability of radiofrequency to coagulate tissues, arresting the microcirculating blood, is in fact responsible for its hemostatic effect [22]. Manikam et al. reported two cases of ruptured HCC in which RFA successfully achieved hemostasis [23]. Sun et al. performed RFA as both salvage therapy and curative treatment for spontaneous rupture of HCC [24]. Cheung et al. reported that the use of RFA for hemostasis during laparotomy greatly reduced the hospital mortality rate when compared with conventional hepatic artery ligation [14].

\section{Conclusions}

In patients with spontaneous HCC rupture the first goal is hemostasis. To date there has been no prospective randomized controlled trial or well-designed comparative study designed to determine the best method of hemostasis. In hemodynamically unstable patients, or when embolization and/or resection are unavailable and/ or unfeasible due to the patient's condition, RFA is a good alternative or could be complementary to the classic emergency surgery. This study has shown that RFA is a safe and simple operative hemostasis method that can also be considered a procedure for life-threatening events in patients with end-stage liver disease. The treatment approach has to be chosen after evaluating liver reserve, liver tumor invasion, and life expectancy. A clear and comprehensive treatment protocol for these scenarios is essential.

\section{Abbreviations \\ AFP: Alpha-fetoprotein; ALT: Alanine aminotransferase; AST: Aspartate aminotransferase; CT: Computed tomography; HCC: Hepatocellular carcinoma; ICU: Intensive care unit; LT: Liver transplantation; MELD: Model for End-Stage Liver Disease; OR: Operating room; POD: Postoperative day; PRBC: Packed red blood cells; RFA: Radiofrequency ablation; SLB: Spontaneous liver bleeding; TAE: Transcatheter arterial embolization}

\section{Acknowledgements}

Not applicable.

\section{Availability of data and materials}

The CT scan is saved in the e-health system of our hospital with the clinical history reported in the case report and is accessible any time if requested by the editor.

\section{Authors' contributions}

AB: writing the paper and review of the literature. FDA: performed the surgery, review of the literature, and final review of the paper. MR: review of the literature. MF: review of the literature. AV: review of the literature. UC: final review of the paper. All authors have agreed to the content of this manuscript and agree with its submission. All authors read and approved the final manuscript.

\section{Competing interests}

The authors declare that they have no competing interests.

\section{Consent for publication}

Written informed consent was obtained from the patient for publication of this case report and any accompanying images. A copy of the written consent is available for review by the Editor-in-Chief of this journal.

Ethics approval and consent to participate Not applicable.

Received: 1 November 2016 Accepted: 3 January 2017

Published online: 01 March 2017

\section{References}

1. Battula N, Tsapralis D, Takhar A, Coldham C, Mayer D, Isaac J, et al. Aetiopathogenesis and the management of spontaneous liver bleeding in the West: a 16-year single-centre experience. HPB (Oxford). 2012;14:382-9.

2. Aoki T, Kokudo N, Matsuyama Y, Izumi N, Ichida T, Kudo M, et al. Prognostic impact of spontaneous tumor rupture in patients with hepatocellular carcinoma: an analysis of 1160 cases from a nationwide survey. Ann Surg. 2014;259:532-42.

3. Leung KL, Lau WY, Lai PB, Yiu RY, Meng WC, Leow CK. Spontaneous rupture of hepatocellular carcinoma: conservative management and selective intervention. Arch Surg. 1999;134:1103-7.

4. Miyamoto M, Sudo T, Kuyama T. Spontaneous rupture of hepatocellular carcinoma: a review of 172 Japanese cases. Am J Gastroenterol. 1991;86:67-71.

5. Chearanai O, Plengvanit U, Asavanich C, Damrongsak D, Sindhvananda K, Boonyapisit S. Spontaneous rupture of primary hepatoma: report of 63 cases with particular reference to the pathogenesis and rationale treatment by hepatic artery ligation. Cancer. 1983;51:1532-6.

6. Clarkston W, Inciardi M, Kirkpatrick S, McEwen G, Ediger S, Schubert T. Acute hemoperitoneum from rupture of a hepatocellular carcinoma. J Clin Gastroenterol. 1988;10:221-5

7. Chan WH, Hung CF, Pan KT, Lui KW, Huang YT, Lin SY, et al. Impact of spontaneous tumor rupture on prognosis of patients with T4 hepatocellular carcinoma. J Surg Oncol. 2016;113:789-95.

8. Zhu LX, Wang GS, Fan ST. Spontaneous rupture of hepatocellular carcinoma. Br J Surg. 1996;83:602-7. 
9. Sato Y, Fujiwara K, Furui S, Ogata I, Oka Y, Hayashi S, et al. Benefit of transcatheter arterial embolization for ruptured hepatocellular carcinoma complicating liver cirrhosis. Gastroenterology. 1985;89:157-9.

10. Chiappa A, Zbar A, Audisio RA, Paties C, Bertani E, Staudacher C. Emergency liver resection for ruptured hepatocellular carcinoma complicating cirrhosis. Hepatogastroenterology. 1999;46:1145-50.

11. Cherqui D, Panis Y, Rotman N, Fagniez PL. Emergency liver resection for spontaneous rupture of hepatocellular carcinoma complicating cirrhosis. Br J Surg. 1993;80:747-9.

12. Ngan H, Tso WK, Lai CL, Fan ST. The role of hepatic arterial embolization in the treatment of spontaneous rupture of hepatocellular carcinoma. Clin Radiol. 1998;53:338-41.

13. Lau KY, Wong TP, Wong WW, Tan LT, Chan JK, Lee AS. Emergency embolization of spontaneous ruptured hepatocellular carcinoma: correlation between survival and Child-Pugh classification. Australas Radiol. 2003:47: 231-5.

14. Cheung TT, Poon RT, Chok KS, Chan AC, Tsang SH, Dai WC, et al. Management of spontaneously ruptured hepatocellular carcinomas in the radiofrequency ablation era. PLoS One. 2014;9:e94453.

15. Lin HM, Lei LM, Zhu J, Li GL, Min J. Risk factor analysis of perioperative mortality after ruptured bleeding in hepatocellular carcinoma. World J Gastroenterol. 2014:20:14921-6.

16. Yoshida H, Mamada Y, Taniai N, Mizuguchi Y, Kakinuma D, Ishikawa Y, et al. Long-term results of elective hepatectomy for the treatment of ruptured hepatocellular carcinoma. J Hepatobiliary Pancreat Surg. 2008;15:178-82.

17. Rijckborst V, Ter Borg MJ, Tjwa ET, Sprengers D, Verhoef $K$, Moelker A, et al. Short article: Management of ruptured hepatocellular carcinoma in a European tertiary care center. Eur J Gastroenterol Hepatol. 2016;28:963-6.

18. Monroe EJ, Kogut MJ, Ingraham CR, Kwan SW, Hippe DS, Padia SA. Outcomes of emergent embolisation of ruptured hepatocellular carcinoma in a western population. Clin Radiol. 2015;70:730-5.

19. Sunderland GT, Chisholm EM, Lau WY, Chung SC, Leung WT, Li AK. Alcohol injection: a treatment for ruptured hepatocellular carcinoma. Surg Oncol. 1992;1:61-3.

20. Hsueh KC, Fan HL, Chen TW, Chan DC, Yu JC, Tsou SS, et al. Management of spontaneously ruptured hepatocellular carcinoma and hemoperitoneum manifested as acute abdomen in the emergency room. World J Surg. 2012; 36:2670-6.

21. Jin YJ, Lee JW, Park SW, Lee Jl, Lee DH, Kim YS, et al. Survival outcome of patients with spontaneously ruptured hepatocellular carcinoma treated surgically or by transarterial embolization. World J Gastroenterol. 2013;19: 4537-44.

22. Lau WY, Lai EC. The current role of radiofrequency ablation in the management of hepatocellular carcinoma: a systematic review. Ann Surg. 2009;249:20-5.

23. Manikam J, Mahadeva S, Goh KL, Abdullah BJ. Percutaneous, non-operative radio frequency ablation for haemostasis of ruptured hepatocellular carcinoma. Hepatogastroenterology. 2009:56:227-30.

24. Sun WB, Ding XM, Ke S, Gao J, Zhang YF. Repeated radiofrequency ablation as both salvage solution and curative treatment for spontaneous rupture of giant medial lobe hepatocellular carcinoma. Chin Med J (Engl). 2009;122: 2067-70.

\section{Submit your next manuscript to BioMed Central and we will help you at every step:}

- We accept pre-submission inquiries

- Our selector tool helps you to find the most relevant journal

- We provide round the clock customer support

- Convenient online submission

- Thorough peer review

- Inclusion in PubMed and all major indexing services

- Maximum visibility for your research

Submit your manuscript at www.biomedcentral.com/submit

) Biomed Central 